\title{
O processo de adoecimento mental do trabalhador da Estratégia Saúde da Família*
}

\author{
The process of becoming mentally ill among Family Health Strategy workers
}

\author{
El proceso de padecimiento mental del trabajador de la Estrategia Salud de la Familia
}

Gisele Santana Pereira Carreiro', Maria de Oliveira Ferreira Filha², Rolando Lazarte³, Antônia Oliveira Silva4, Maria Djair Dias ${ }^{5}$

\begin{abstract}
* Esta pesquisa representa os resultados parciais do estudo intitulado "O impacto do trabalho na saúde mental dos profissionais da Estratégia Saúde da Família", desenvolvida como requisito para a obtenção do título de mestre do Programa de Pós-Graduação em Enfermagem da Universidade Federal da Paraíba.

1 Enfermeira, Mestre em Enfermagem. Professor Assistente I da Universidade Federal do Rio Grande do Norte. Natal, RN, Brasil. E-mail: giselesps@yahoo.com.br.

${ }^{2}$ Enfermeira, Doutora em Enfermagem. Professora Adjunta IV do Departamento de Enfermagem da Universidade Federal da Paraíba (UFPB). João Pessoa, PB, Brasil. E-mail:marfilha@yahoo.com.br.

${ }^{3}$ Bacharel em Ciências Políticas e Sociais, Doutor em Sociologia. João Pessoa, PB, Brasil. E-mail: elzara@yahoo.com.br.

${ }^{4}$ Enfermeira, Doutora em Enfermagem Fundamental. Professora Associada IV do Departamento de Enfermagem da UFPB. João Pessoa, PB, Brasil. E-mail: alfaleda@hotmail.com.

${ }^{5}$ Enfermeira, Doutora em Enfermagem. Professora Associada II do Departamento de Enfermagem da UFPB. João Pessoa, PB, Brasil. E-mail: mariadjair@yahoo.com.br.
\end{abstract}

\section{RESUMO}

Trabalhadores da Estratégia Saúde da Família enfrentam situações que acarretam desgaste psíquico. O objetivo do presente estudo foi conhecer o processo de adoecimento mental desses trabalhadores e os fatores desencadeantes. Trata-se de estudo fundamentado na epidemiologia social, de abordagem qualitativa, realizado com 36 trabalhadores de 17 Unidades de Saúde da Família de João Pessoa/PB, no período de maio a julho de 2009. Foram realizadas entrevistas semiestruturadas, analisadas pelo software Alceste 4.8, resultando em quatro classes temáticas: organização do processo de trabalho; sobrecarga de trabalho e demandas pessoais; família e relações contraditórias; estresse e problemas de saúde de pessoas significativas. Dos participantes da pesquisa, 22 adoeceram, principalmente devido à distúrbios de ansiedade, sendo o trabalho a causa indicada. Esse fato aponta que a promoção da saúde dos trabalhadores deve ocorrer dentro e fora dos locais de trabalho, já que o trabalhador do sistema de saúde também necessita ser cuidado.

Descritores: Enfermagem; Estresse Psicológico; Saúde da Família; Saúde do Trabalhador.

\section{ABSTRACT}

Family Health Strategy Workers deal with situations that eventually lead to psychological distress. The objective of the present study was to understand these workers' process of becoming mentally ill and the triggering factors. This qualitative study is founded on social epidemiology, and was performed with 36 workers of 17 Family Health Units of João Pessoa, Paraíba, Brazil, between May and July 2009. Semi-structured interviews were performed and then analyzed using Alceste 4.8, revealing four thematic classes: organization of the working process; work overload and personal demands; family and conflicting relationships; stress and health issues of significant others. Twenty-two subjects became ill, mainly due to anxiety disorders, with work being the indicated cause. This fact suggests that the promotion of workers' health should take place outside their work area, as health system workers must also be cared for.

Descriptors: Nursing; Stress, Psychological; Family Health; Occupational Health.

\section{RESUMEN}

Los trabajadores de la Estrategia Salud de la Familia enfrentan situaciones que acarrean desgaste psíquico. El estudio objetivó conocer el proceso de padecimiento mental de estos trabajadores y los factores desencadenantes. Estudio fundamentado en epidemiología social, de abordaje cualitativo, realizado con 36 trabajadores de 17 unidades de Salud de la Familia de João Pessoa-PB, de mayo a julio de 2009. Se realizaron entrevistas semiestructuradas, analizadas con software Alceste 4.8, llegándose a cuatro clases temáticas: organización del proceso de trabajo, sobrecarga de trabajo y demandas personales, familia y relaciones contradictorias, y estrés y problemas significativos de salud de las personas. De los participantes, 22 padecieron, principalmente, de disturbios de ansiedad; indicándose al trabajo como la causa desencadenante. Tal hecho expresa que la promoción de salud de los trabajadores debe suceder dentro y fuera de los lugares de trabajo, ya que el trabajador del sistema de salud necesita también de ser cuidado.

Descriptores: Enfermería; Estrés Psicológico; Salud de la Familia; Salud Laboral. 


\section{INTRODUÇÃO}

Ao longo do tempo, o mundo do trabalho sofreu profundas mudanças decorrentes da transição de uma economia baseada na comercialização de produtos manufaturados à industrialização. Hoje, vivemos na era da globalização e presenciamos a fragmentação e diversificação da classe trabalhadora, bem como, verificamos a perda de direitos e sentidos, devido ao caráter destrutivo do capital vigente ${ }^{(1-2)}$.

Além disso, à competitividade no mercado de trabalho soma-se o medo do desemprego, induzindo as pessoas a se submeterem às condições de trabalho desumanas: baixos salários, ambientes insalubres, ruídos e calor excessivos, acúmulo de funções, jornadas de trabalho que excedem a carga horária suportável, regime em turnos alternantes, e muitas vezes, ainda enfrentam a falta de equipamento de proteção individual (EPIs), o que contribui significativamente para mudança no perfil epidemiológico do adoecimento dos trabalhadores(2).

Os trabalhadores da saúde também enfrentam essa dura realidade, em especial os que atuam na Estratégia Saúde da Família (ESF). Estes estão submetidos a diversas situações que vão desde riscos biológicos, como exposição a materiais tóxicos e contaminação, como também fatores relativos à organização e precarização do trabalho, como a divisão e o parcelamento das tarefas, falta de reconhecimento profissional, multifuncionalidade, exigência de produtividade, baixos salários, inexistência de trabalho em equipe, deficiências dos demais níveis do sistema de saúde, inexistência de discussão sobre plano de cargos e salários e arrocho salarial a que o setor da saúde é submetido, e até mesmo, perseguição política(2-7).

A saúde dos trabalhadores da saúde é esquecida tanto pelos gestores, que não se preocupam em cuidar dos seus cuidadores, como pelos próprios profissionais, que evitam o afastamento para evitar a perda salarial associado ao sentimento de não poder ficar doente por ser responsável pela saúde de outros. Muitas vezes, as sobrecargas de trabalho passam despercebidas ou são tidas como "naturais" pelos próprios trabalhadores, que consideram "ossos do oficio"(5).

Estudos realizados sobre transtornos mentais relacionados ao trabalho estimam índices de $30 \%$ de transtornos mentais menores e de $5 \%$ a $10 \%$ de transtornos mentais graves na população trabalhadora ocupada. Na literatura, a prevalência de Transtornos Mentais Comuns (TMC) varia entre $7 \%$ e $30 \%$ e estudos brasileiros descrevem taxas entre $22,7 \%$ e $35 \%{ }^{(8-9)}$.

No Brasil, as pesquisas sobre o sofrimento mental dos trabalhadores da ESF ainda são insuficientes, entretanto muitas pesquisas apontam o processo de trabalho em saúde, hospitalar ou na Atenção Primária, como responsável pelo desgaste emocional do trabalhador, o que influencia diretamente no seu desempenho no trabalho e na sociedade (absenteísmo, queda da produtividade, alta rotatividade de profissionais, elevação da demanda dos serviços de saúde, dificuldades de relacionamento em casa, uso abusivo de tranquilizantes, álcool e outras drogas) ${ }^{(5-9)}$.

Em pesquisa realizada com 116 agentes comunitários de saúde (ACS), encontrou-se que $75 \%$ dos entrevistados apresentaram um nível de ansiedade considerado moderado e $17,24 \%$, apresentaram ansiedade grave. Um outro estudo realizado com 141 ACS identificou a síndrome do esgotamento profissional (burnout) em $24,1 \%$ da amostra e de TMC em 43,3\% na mesma amostra, ou seja, acima das taxas encontradas em outros estudos ${ }^{(8-}$ 9).

A ESF é uma estratégia de reorganização e fortalecimento da atenção básica como o primeiro nível de atenção à saúde, plenamente sintonizada com os princípios filosóficos do Sus de universalidade, equidade e integralidade, sendo a família, ou seja, a coletividade, o seu foco de atenção, pois considera que o indivíduo não pode ser compreendido de forma isolada, como ocorre no modelo biomédico(10).

Os trabalhadores que atuam na Atenção Básica, especificamente nas Equipes de Saúde da Família, são responsáveis pela avaliação dos indicadores de saúde de sua área, reconhecimento da realidade das famílias sob sua responsabilidade, identificação e elaboração de estratégias de enfrentamento dos problemas de saúde mais comuns, desenvolvimento de ações educativas, além de prestar assistência direta aos usuários, na unidade e também em visitas domiciliares ${ }^{(11)}$. Assim, o modelo de assistência pressupõe que deve haver o envolvimento da equipe com a população e entre si para resolução de problemas detectados, o que pode gerar certo gasto de energia e adaptação que, somadas às características de cada trabalhador podem desencadear o processo de sofrimento mental $(9,12)$. 
Como fator agravante, ainda existem as limitações enfrentadas pelos profissionais para resolver os problemas encontrados, seja por falta de qualificação profissional, modelo de gestão impróprio, escassez de recursos materiais, dentre outros. Observa-se que são delegadas aos profissionais múltiplas tarefas com um alto grau de exigências e responsabilidades, as quais, dependendo do ambiente, da organização do trabalho e do preparo para exercer seu papel, podem criar tensão para eles, equipe e comunidade assistida ${ }^{(10)}$.

Esta pesquisa é o aprofundamento de um estudo anterior sobre depressão e ansiedade em trabalhadores da ESF realizado entre os anos de 2006 e 2007, em que 145 profissionais de Unidades de Saúde da Família do município de João Pessoa-PB, foram submetidos ao Self Report Questionaire - SRQ-20, que identifica tendência ao adoecimento mental. Destes profissionais, encontramos 49 em situação de vulnerabilidade, ou seja, cujos fatores associados eram a perda de pessoas significativas, insatisfação com o trabalho e com o salário, falta de reconhecimento pelos usuários e pelos colegas de trabalho/gestão, sobrecarga de trabalho, influência negativa do trabalho na relação com os familiares e falta de tempo para o lazer ${ }^{(13)}$.

Como grande parte dos fatores estavam associados a situações vivenciadas no trabalho e tendo a inquietação de saber se estas pessoas haviam adoecido ou não, partimos para uma pesquisa fundamentada na epidemiologia social e na Psicodinâmica do Trabalho (PDT), que abrange questões referentes à gênese e às transformações do sofrimento mental vinculadas à organização do trabalho ${ }^{(14)}$. Portanto, este estudo teve como objetivo conhecer o processo de adoecimento dos trabalhadores da ESF que apresentaram tendência para o adoecimento mental, bem como os possíveis fatores desencadeantes desse processo.

\section{METODOLOGIA}

Utilizando o método da epidemiologia social, de cunho retrospectivo, tentamos compreender como ocorreu o processo de adoecimento mental nos trabalhadores da ESF identificando os possíveis fatores desencadeantes. Escolhemos este paradigma, uma vez que o conhecimento epidemiológico se desenvolve em torno do esforço para explicar os problemas de saúdedoença em sua dimensão social, tornando o objeto de estudo da epidemiologia fenômeno saúde-doença como processo particular da sociedade(15). Quanto à abordagem, utilizamos a qualitativa, pois necessitávamos conhecer a dimensão subjetiva do sofrimento e por meio dos relatos dos trabalhadores vislumbramos uma aproximação maior com a realidade, sendo possível analisar as implicações do trabalho na saúde mental dos profissionais da ESF.

O material empírico foi produzido entre os meses de Maio e Julho de 2009 por meio de entrevista. Inicialmente foi realizada, junto à Secretaria Municipal de Saúde, a localização dos profissionais identificados como vulneráveis ao adoecimento no estudo anterior. Dos 49 profissionais com risco para adoecimento mental, foram localizados 36. No primeiro contato, cada profissional foi informado sobre os objetivos e procedimentos da pesquisa, bem como, da possibilidade de recusar ou retirar seu consentimento em qualquer etapa. Em seguida, as entrevistas foram realizadas ou agendadas, respeitando a disponibilidade de cada participante. Todos os profissionais entrevistados assinaram o Termo de Consentimento Livre e Esclarecido, no momento da entrevista.

A primeira parte da coleta de dados constituiu-se de uma entrevista estruturada, que abordava dados profissiográficos e identificava os profissionais que adoeceram ou não de algum distúrbio depressivo ou ansioso, entre os anos de 2007 e 2009. Em seguida, os trabalhadores que apresentaram algum diagnóstico de transtorno, realizado por um médico clínico ou psiquiatra, foram submetidos a um roteiro semiestruturado, sobre possíveis fatores que levaram ao adoecimento, na opinião dos mesmos.

Após a realização das entrevistas, as mesmas foram transcritas, e constituíram um banco de dados que foi submetido ao software Alceste 4.8. O Alceste (Analyse Lexicale par Contexte d'un Ensemble de Segment de Texte) é um programa que classifica de maneira semiautomática as palavras para o interior de um corpus. Para isso, o programa segmenta o texto, estabelece as semelhanças entre os segmentos e hierarquias de classes de palavras.

O processo de análise ocorre com as seguintes etapas: identificação das palavras e de suas formas reduzidas (raízes) e constituição de um dicionário; segmentação do material discursivo em Unidades de 
Contexto Elementares (UCE); delimitação de classes semânticas, seguida de sua descrição através da quantificação das formas reduzidas e função das UCE, bem como das ligações estabelecidas entre elas; análise da associação e correlação das variáveis informadas às classes obtidas; análise das ligações estabelecidas entre as palavras típicas em função das classes (dendograma) ${ }^{(16)}$.

Quando submetemos o material empírico para leitura por meio do Alceste, este revelou um corpus constituído por 36 UCIs (Unidades de Contexto Iniciais), resultando na seleção 790 UCEs, sendo que destas, 610 foram classificadas, ou seja, obtiveram um aproveitamento de $77,22 \%$ das UCEs selecionadas. O corpus foi composto por 3.610 palavras diferentes, sendo descartadas pelo programa as palavras com frequência igual ou inferior a quatro, e qui-quadrado menor que 3,84. Após a redução em suas raízes, obtiveram-se 2.129 palavras analisáveis, 321 palavras instrumentais e 50 palavras variáveis. Após análise, surgiram quatro classes semânticas referentes aos fatores causadores do adoecimento mental que serão discutidas a seguir.

A pesquisa atendeu a Resolução 196/96 - Ministério da Saúde/Conselho Nacional de Saúde/Comissão Nacional de Ética em Pesquisa e as Diretrizes e Normas que regem pesquisa envolvendo seres humanos, sendo aprovada conforme declaração emitida pelo Comitê de Ética em Pesquisa da Secretaria de Saúde do Estado da Paraíba sob protocolo CAAE-1154.0.000.349-09.

\section{RESULTADOS E DISCUSSÃO}

\section{o processo de adoecimento: revelando a multifatorialidade do sofrimento}

Dos 36 trabalhadores em risco de adoecimento, 22 $(61,1 \%)$ referiram que adoeceram. Prevaleceram os profissionais do sexo feminino, com idade entre 31 e 40 anos, estado civil casado, que trabalham na ESF há mais de cinco anos, recebendo entre um e cinco salários mínimos, que desempenham a função de Agente Comunitário de Saúde, o que pode ser explicado pelo fato de a maioria dos trabalhadores que atuam na ESF ser mulheres e os ACS são os profissionais em maior número dentro da equipe ${ }^{(6)}$. Dentre estes, 19 (86,3\%) referiram que sofreram com algum distúrbio de ansiedade, enquanto que três $(13,7 \%)$ apresentaram transtorno depressivos.

\section{Classe 1: Organização do processo de trabalho}

A Classe 1 foi constituída por 146 UCE, tendo aproveitamento de $23,93 \%$ e as seguintes palavras associadas significativamente: apoiadores, comunidade, Distrito Sanitário, estrutura, gestão, metas, reclamar, reunião, unidade.

Pela associação das palavras acima descritas, percebe-se que o modelo de gestão no qual os trabalhadores atuam é vertical e hierarquizado em cargos e funções. O trabalhador da ESF está na porta de entrada do sistema, portanto em uma das pontas dessa cadeia hierárquica e não tem acesso direto aos gestores de distritos sanitários, nem ao secretário de saúde. Para isso, existem os Apoiadores Técnicos, profissionais de nível superior que atuam como intermediários entre a ESF e a gestão do Distrito Sanitário e se reúnem semanalmente com a equipe. Eles realizam visitas frequentes as unidades de saúde, e depois relatam para a gestão as dificuldades encontradas nas unidades visitadas. Alguns trabalhadores afirmam que a presença do apoiador não é suficiente para resolver os problemas da Unidade, pois segundo eles, os apoiadores não têm autonomia para decidir. Os relatos a seguir mostram essa cadeia complexa de relacionamentos burocratizados:

Às vezes, tem até uma coisa para reclamar, na reunião a gente coloca os problemas da área, e os problemas da gente também, depois a gente passa para as apoiadoras e elas levam os problemas para o Distrito Sanitário.

O relato acima mostra que a reclamação foi adotada como uma estratégia coletiva de defesa. Através da reclamação um indivíduo pode se estabelecer ou restabelecer-se no grupo, uma vez que ele tem a possibilidade de compartilhar com os colegas os sofrimentos e angústias produzidas pelo processo de trabalho e, portanto, modificar a organização do trabalho(17).

As principais causas de reclamação relatadas pelos trabalhadores se referem às condições de trabalho, corroborando com outros estudos ${ }^{(5-6,18)}$. A maioria das unidades do município funciona em casas alugadas pela prefeitura, e muitas vezes, são casas antigas, em 
condições que põem em risco a saúde dos trabalhadores e usuários (paredes mofadas, teto com infiltração, esgoto aberto). Apenas as Unidades Integradas, que foram construídas recentemente, possuem estrutura adequada. Geralmente, em cada Unidade Integrada existem quatro Equipes de Saúde da Família, cada uma com sua área de abrangência bem delimitada. Apesar de possuírem uma estrutura física satisfatória, os trabalhadores dessas unidades colocam como dificuldade a organização do processo de trabalho, uma vez que foram inseridos outros profissionais, além de dificuldades de convivência com outras equipes.

A dificuldade de se trabalhar em equipe também foi citada em outros estudos. A falta de planejamento coletivo e individualização das tarefas determinam uma prestação do cuidado fragmentada não contemplando as diversas necessidades de saúde dos usuários, descaracterizando a ideia do que deve ser o processo de trabalho na ESF(6).

A saúde mental é influenciada diretamente pelas condições onde se desempenha o trabalho. Estudos apontam que o nível de satisfação profissional poderia ser maior se houvesse mais investimentos para a melhoria da infraestrutura física dos serviços em geral. Assim, quando existem boas condições de trabalho os resultados alcançados podem superar as expectativas, caso contrário, os objetivos do trabalho podem não ser alcançados, influenciando de forma negativa a saúde do trabalhador, refletindo, sobretudo, na saúde da comunidade(19-20).

Um estudo realizado com médicos que atuam na ESF apontou como fator responsável pelo esgotamento emocional e baixa realização profissional a discrepância entre a formação profissional e a proposta de processo de trabalho da ESF, causando uma limitação no desempenho do papel do profissional, pois os trabalhadores reconhecem que ainda predomina na Atenção Básica a ideia de medicina curativa e não preventiva, fato que é agravado pela falta de suporte organizacional(21).

Apesar do aumento do número de cursos (especializações, residências multiprofissionais) na área de Saúde da Família, percebe-se que muitos profissionais da ESF passaram apenas pelo curso introdutório, insuficiente para o desenvolvimento das habilidades exigidas pelo novo processo de trabalho: cuidar das famílias, respeitando suas necessidades, e não apenas cuidar da doença de um indivíduo(18).

Constata-se ainda nos relatos que, apesar de existirem reuniões frequentes com a gestão, os trabalhadores da ESF não têm poder de decisão para resolver problemas do cotidiano e a falta de autonomia do trabalhador na organização do processo de trabalho também é considerada como um fator de desgaste psíquico. A carga psíquica aumenta quando a liberdade de organização no trabalho diminui. Assim, existe um conflito entre os trabalhadores e os interesses da gestão(14).

Além das condições precárias de trabalho, a imposição do cumprimento de metas também foi considerada pelos trabalhadores como um fator determinante no processo de adoecimento mental, uma vez que significou aumento da carga de trabalho, consumindo mais forças físicas e mentais, além de ter reduzido o tempo dedicado à família e ao lazer. O relato a seguir evidencia essa sobrecarga:

Com essas histórias de metas, que a gente tem que atingir... Para os outros, pode até estar correndo tranquilo, mas pra mim, está me deixando cansada de correr. Além de correr atrás para atingir as metas, tem as atividades que a gente tem que desenvolver dentro da unidade.

Existe uma pactuação de indicadores entre Ministério da Saúde e municípios, através do Pacto pela Saúde. Contudo, há no município de João Pessoa, a dificuldade em atingir alguns desses indicadores. Portanto, o trabalho na ESF é um trabalho prescrito, ou seja, imposto. No entanto, no ato da execução das tarefas, o trabalhador se encontra com uma defasagem entre o que é pedido e a prática, considerado como o trabalho real. Assim, o trabalhador cria métodos para atender ao máximo o que é prescrito, e nem sempre consegue, o que gera sério desgaste emocional pois eles se sentem responsáveis pelo sistema de saúde e esquecem que muitas vezes, os problemas e os desafios são de ordem mais complexas, passando pelas questões da gestão do trabalho(5).

Como forma de incentivar os trabalhadores a cumprirem as exigências do MS, o município implantou a gratificação por produção de indicadores, denominada de Valor Pecuniário Individual - VPI, em que a equipe necessita atingir um determinado número de 
atendimentos, incluindo esses indicadores, para receber o valor total da gratificação.

A avaliação desses indicadores é feita trimestralmente. Se a equipe atingir apenas um indicador, nenhum valor é recebido; caso a equipe consiga atingir de dois a três indicadores, cada membro recebe $50 \%$ do valor da gratificação; se forem atingidos quatro ou cinco indicadores, recebe-se $80 \%$ do valor. Apenas se são atingidos todos os indicadores recebe-se o valor total. Nessa perspectiva, pode-se afirmar que a gestão adota a visão taylorista, sobre o processo de trabalho, em que o objetivo final é alcançar a máxima produtividade, ficando a qualidade da assistência em segundo plano.

A adoção desta medida é uma tentativa de atingir um determinado número de procedimentos e atendimentos, entretanto alguns profissionais relataram que a cobrança aumentou e cada profissional se sente responsável, pois se um membro da equipe não conseguir atingir os indicadores, toda a equipe fica sem receber ou recebe apenas uma parte do valor da gratificação. Isso provoca entre outras questões, relações de competitividade, policiamento e agressão entre os trabalhadores. Além disso, existe a insatisfação com a disparidade do valor da gratificação para cada profissional.

Para se conseguir aumento na produtividade, o modo de produção taylorista propôs métodos e sistemas de racionalização do trabalho e disciplina do conhecimento operário colocando-o sob o comando gerencial do processo e sob uma rígida hierarquização, além de ocorrer fragmentação do trabalho, o que acarreta em desequilíbrios nas cargas de trabalho. Assim, percebe-se outra característica taylorista presente no cotidiano dos trabalhadores da ESF, o alto grau de normatização para implementação, uma vez que, as normas são regulamentadas centralmente pelo Ministério da Saúde e devem ser seguidas rigorosamente pelos municípios ${ }^{(14,22-}$ 23).

Essa obrigatoriedade no cumprimento das normas ditadas pelo Ministério da Saúde limita a proposta da Estratégia Saúde da Família, uma vez que não permite a elaboração de estratégias para as realidades distintas das diferentes comunidades em todo o território nacional ${ }^{(23)}$.

\section{Classe 2: Influência do trabalho e demandas pessoais}

A Classe 2 foi formada por 87 UCE, com aproveitamento de $14,89 \%$, tendo as seguintes palavras associadas significativamente: ansiedade, atrapalhar, casa, depressão, pressão, saúde mental, trabalho, estava.

Nesta classe, os trabalhadores descrevem a influência do trabalho na saúde mental, evidenciada pela dificuldade nas relações em casa e no trabalho, resultantes da sobrecarga de trabalho. Esta sobrecarga também advém da dupla, e muitas vezes, tripla jornada de trabalho, decorrente de outros vínculos empregatícios, bem como do trabalho doméstico, o que também diminui o tempo que é dedicado à família e ao lazer. Vejamos os relatos a seguir:

Eu estou vivendo o trabalho, de manhã, de tarde, de noite $e$ de madrugada. De madrugada eu estou sonhando com o trabalho. E sem tempo nenhum pra lazer. (...) Ai eu fico querendo dar uma cobertura maior aos filhos pra compensar a situação que me cobram demais. Eu já saio daqui extremamente cansada, quando chego em casa pra dar assistência aos filhos.

O aumento do tempo dedicado ao trabalho, decorrente do aumento da jornada de trabalho, determina uma redução do tempo de convivência familiar, tornando-se motivo de angústia, principalmente no que se refere à convivência com os filhos. Esta sobrecarga de trabalho advém da precarização das condições de trabalho e da baixa remuneração, pois os trabalhadores procuram outros vínculos empregatícios como forma de garantir melhores condições de vida. O cansaço sofre um processo de cronificação, sacrificando as horas do não-trabalho que seriam dedicadas ao convívio familiar e às outras atividades sociais, além disso, pode haver comprometimento das outras atividades laborais ${ }^{(7)}$.

A sobrecarga de trabalho, não só pelo aumento das atribuições individuais, como também pela falta de recursos humanos, aliada à carga horária dedicada a ESF também dificultam a realização de capacitações e cursos pelos profissionais, já que os trabalhadores devem trabalhar oito horas diariamente ${ }^{(18)}$.

Além de significar mais horas de trabalho, a dupla/tripla jornada supõe uma divisão emocional entre as exigências do trabalho e das necessidades da família, 
gerando com frequência uma dupla culpabilidade, tornando as mulheres mais vulneráveis ao desgaste mental(24).

O trabalho doméstico, além de ser uma extensão da jornada de trabalho, contribui significativamente para a fadiga e exaustão física. Trata-se de uma atividade que não tem descanso semanal, nem férias remuneradas. Some-se a isso o fato de ser uma atividade desvalorizada socialmente, e que, muitas vezes, não consegue elevar a autoestima da trabalhadora.

O trabalho produz sofrimento quando constrói uma imagem de indignidade, um sentimento de inutilidade, tornando-se um trabalho despersonalizado e sem significação. Quando, ao contrário, o trabalhador consegue identificar significação humana e social na sua atividade, quando ela tem significado para a família, para os amigos, quando consegue despertar sentimento de utilidade, o trabalho constitui como uma fonte de satisfação e prazer ${ }^{(14)}$.

Não são todos os trabalhadores que podem organizar o lazer de acordo com suas necessidades e seus desejos, uma vez que, desfrutar de atividades fora do trabalho também tem um custo financeiro que nem todos podem pagar. Trata-se não apenas de uma contaminação, mas de uma estratégia para não deixar "apagar o condicionamento mental ao comportamento produtivo", o que contribui diretamente para o processo de cronificação do cansaço, pois a realização de atividades que produzem momentos de descontração e prazer podem absorver o impacto de agentes estressores ${ }^{(7,14)}$.

O quadro de desemprego estrutural, que marca o mercado de trabalho atual, deixa os trabalhadores apreensivos e mais submissos às relações precárias de trabalho. A ameaça de demissão, principalmente aos trabalhadores que não tem estabilidade no emprego, constantemente, produz sofrimento psíquico, uma vez que a demissão significa uma ruptura dos padrões de vida e das relações sociais.

\section{Classe 3: A família e as relações contraditórias.}

A Classe 3 foi formada por 76 UCE, com aproveitamento de $31,52 \%$, tendo as seguintes palavras associadas significativamente: ajudar, conversa, desabafar, digo, dizer, errar, falar, família, filhos, irmão, mãe, marido, pais, pessoas, problema, vida.
Esta classe descreve a influência da família no desempenho do trabalhador. A família é considerada a principal responsável pela formação da consciência do indivíduo. Ela é essencial no processo de construção da identidade, pois é a responsável pela transmissão de crenças, valores e normas. Em qualquer processo de socialização, a influência da família desempenha papel primordial. Assim, estando o ser humano intrinsecamente ligado à família e ao meio social, considera-se que esses atuam como fonte de pressões, mas também como apoio, na medida em que constituem-se um meio de convivência onde é possível desabafar e compartilhar os problemas. Vejamos o relato a seguir:

Minha família, graças a Deus é bem unida, todo mundo se entende, pai, mãe, os filhos também. Dinheiro falta, mas harmonia e união não faltam. É o que me deixa também uma pessoa equilibrada.

A família estruturada emocionalmente torna-se fonte de apoio para o trabalhador que se sente compreendido e apoiado nas suas fragilidades afetivas; o que não significa dizer que uma família com ausência de conflitos é responsável pelo desenvolvimento emocional e psíquico satisfatórios de seus membros, pois, muitas famílias não expõem suas emoções para evitar o clima de tensão entre seus membros. É o que se denomina evitação de conflito. Entretanto, a busca pela solução dos problemas da família podem ter papel crucial no bom desenvolvimento psíquico do indivíduo(23).

Em outros relatos dos entrevistados foram evidenciados como fator associado ao sofrimento psíquico, situações de conflitos familiares, incluindo dificuldade de relacionamento com os filhos e com o cônjuge, problemas de saúde ou perda de ente querido.

Sempre ajudei minha familia. Como eu não tive filhos, as responsabilidades são todas nas minhas costas. Tem semana que eu estou mais carregada. Tudo é comigo. Eu estou muito pressionada. Eu acabo absorvendo os problemas de todo mundo. o povo se admira porque eu sou estressada, mesmo não tendo filho e nem marido, mas eu tenho uma família.

No fragmento acima percebe-se que há sentimentos contraditórios em relação à família: tristeza e raiva pela não valorização do papel que o trabalhador desempenha na família e sentimento de pertencimento; ou seja, 
mesmo triste com a desvalorização a pessoa se sente vinculada a um clã. Este sentimento de pertencimento, enraizamento é fundamental para a manutenção da saúde mental.

Cada pessoa necessita de suporte afetivo para manter-se em equilíbrio. A família constitui um dos pilares desse suporte com a qual é possível compartilhar as preocupações e esperanças, de modo que sua presença possa trazer sentimentos de segurança, conforto e confiança ${ }^{(9)}$. Assim, relações familiares difíceis podem causar a ruptura desse suporte afetivo, afetando diretamente a saúde mental do indivíduo.

Além dos aspectos familiares que são importantes para a saúde mental de seus membros, é necessário também considerar a constituição da personalidade das próprias pessoas. Portanto, muito além da estrutura familiar, as atitudes de seus membros são determinantes para o bem estar geral. Da mesma forma que a angústia e os transtornos psíquicos podem ser atribuídos às relações familiares, a ausência de uma família também pode ser motivo de sofrimento. Isso se deve à incansável busca do ser humano, pelo equilíbrio entre aquilo que é desejável e aquilo que é possível; muitas vezes toma-se como padrão de felicidade o que é desejável, distanciando-se do que é possível(25).

\section{Classe 4: Stress e problemas de saúde de pessoas significativas.}

Esta classe foi formada por 43 UCE, com aproveitamento de $7,29 \%$, tendo as seguintes palavras associadas significativamente: começo, depressão, doenças, filhos, médico, pensar, foi, fui. Nela estão incluídas outras situações vivenciadas pelos trabalhadores que contribuíram para o surgimento do sofrimento psíquico. Vejamos o relato a seguir:

Meu outro filho começou a se tremer, fez os mesmos exames e descobriu que tem a mesma doença, porque é uma doença genética. Então foi o momento que eu pensava que ia perder os dois, então eu entrei em depressão. E eu pedi muito a Deus que eu não entrasse, porque se eu tivesse não tinha ninguém para cuidar deles, porque eles dois ficaram acamados.

O sofrimento mental descrito nos relatos acima se refere a presença de doenças em pessoas muito significativas. Há ainda outros relatos de crises de pânico após situações estressantes, como por exemplo, acidente sofrido pelo profissional. Embora nesta pesquisa os relatos extraídos dos depoimentos focalizaram-se nos aspectos do trabalho que influenciaram o processo de adoecimento mental, percebe-se que este não foi o único desencadeante.

É importante considerar que as pessoas respondem às situações de forma individual, pois possuem diferentes níveis de tolerância à situações estressantes. Algumas são perturbadas por mudanças mínimas, outras são afetadas apenas por estressores de maior magnitude e complexidade. Há ainda pequenos eventos do dia a dia que podem agir de maneira cumulativa e transformar-se em grandes fontes de sofrimento mental. Portanto, é necessário considerar o trabalhador como um sujeito ativo pensante, que ama, chora, deseja, sonha, fantasia a realidade e busca um mundo melhor. Ele não é um homem-máquina, um "robot copy", mas alguém que tem um espaço social definido, com laços sociais e afetivos que vão junto com ele para a sala de atendimento na $\mathrm{USF}^{(9)}$.

Para se alcançar o ideário do SUS, é necessário que haja preocupação igual tanto com os usuários, mas também com os trabalhadores, pois estes são "os verdadeiros operadores da política de saúde", mas também são cidadãos, e como tais, têm o direito de receber cuidados e ser acolhidos em seu sofrimento.

\section{CONSIDERAÇÕES FINAIS}

Os relatos dos trabalhadores sujeitos do estudo evidenciaram a mutifatorialidade do processo de adoecimento, sendo que os fatores associados ao trabalho foram predominantes. Ressalta-se que a sobrecarga de trabalho, a precarização do emprego, a falta de condições adequadas para o desenvolvimento do trabalho, a pressão advinda da gestão, a falta de autonomia para resolver problemas, tiveram importância fundamental como fatores desencadeantes no contexto onde estes trabalhadores atuam.

Não menos importante para o adoecimento, mas pouco referidos, foram as situações de conflito familiar, presença de doença em pessoas significativas da família e falta de apoio da família nuclear. Os trabalhadores deste estudo em sua maioria, são mulheres, casadas, com filhos e com responsabilidades fundamentais no grupo familiar, 
tanto do ponto de vista econômico como afetivo, tendo portanto, um duplo papel a cumprir: mãe, dona de casa, cuidadora do lar e mulher-esposa versus trabalhadora, profissional, cuidadora da saúde da coletividade. Essa duplicidade de ações gera conflitos que acirram-se devido aos papéis de gênero, mas também por imposições sociais, culturais e religiosas, atribuídos à função da mulher e ao lugar que ela ocupa na sociedade atual.

Reconhece-se que há uma certa negligência com a saúde dos trabalhadores do SUS, e este fato merece ser destacado, pois é através deles que a política de saúde ganha vida e concretiza-se no cotidiano dos cidadãos brasileiros. É necessário proporcionar melhor qualidade de vida para os trabalhadores. Neste sentido, entendemos que a promoção da saúde dos trabalhadores deve ocorrer dentro e fora dos locais de trabalho, onde exista a possibilidade de desenvolver tarefas que proporcionem o bem-estar do trabalhador, o que acarretará em melhoria de atendimento prestado aos usuários. Afinal, o trabalhador do SUS também necessita ser cuidado por este mesmo sistema de saúde.

A prevenção do sofrimento mental requer uma ação integrada, articulada entre os setores assistenciais e da vigilância. $O$ atendimento ao trabalhador em situação de sofrimento deve ser realizado por uma equipe multiprofissional, com abordagem interdisciplinar, capacitada para lidar com o sofrimento psíquico do trabalhador. Para tanto, é necessário qualificar profissionais para o atendimento ao trabalhador em situação de sofrimento.

Apesar deste estudo não poder ser generalizado, por se tratar de um contexto específico, entende-se que em outros contextos similares, pode-se identificar um fenômeno semelhante, pois já existem inúmeros estudos mostrando a influência do trabalho no desgaste psíquico dos trabalhadores do SUS. Contudo, ainda há muito o que se descobrir, uma vez que o processo de adoecimento é multifatorial e dinâmico. Assim sendo, é necessário, ainda, o incentivo à realização de pesquisas nessa área que forneçam subsídios importantes no planejamento de uma Política de Saúde do Trabalhador eficaz, contando, inclusive, com a participação dos trabalhadores na elaboração dessas políticas.

Esperamos que o estudo alerte os gestores sobre a real situação de saúde dos trabalhadores da ESF, atentando, principalmente, sobre a importância de fóruns de discussão onde os trabalhadores possam colocar suas dificuldades e necessidades. Assim, é possível minimizar o sofrimento oriundo do trabalho, evitando que este se torne fator desencadeante do adoecimento e volte a ser uma forma de desenvolvimento pessoal e social. Pois como dizia Freud, "saúde mental é poder amar e trabalhar."

Available from:

http://periodicos.ufpb.br/ojs2/index.php/rbcs/article/viewFile/ $10564 / 6816$

6. Marqui $A B T$, Jahn AC, Resta DG, Colomé ICS, Rosa N, Zanon

T. Caracterização das equipes da Saúde da Família e de seu processo de trabalho. Rev Esc Enferm USP. [Internet]. 2010 [cited 2012 sep 18];44(4):956-61. Available from: http://www.scielo.br/pdf/reeusp/v44n4/14.pdf

7. Trindade LL, Lautert L. Síndrome de Burnout entre os trabalhadores da Estratégia de Saúde da Família. Rev Esc Enferm USP 2010 [cited 2009 nov 18]; 44(2):274-9. Available from: http://www.scielo.br/pdf/reeusp/v44n2/05.pdf 8. Silva ATC, Menezes PR. Esgotamento profissional e transtornos mentais comuns em agentes comunitários de saúde. Rev Saúde Pública. [Internet]. 2008 [cited $2012 \mathrm{sep}$ 16];42(5):921-9. Available from: http://www.scielo.br/scielo.php?pid=S0034$89102008000500019 \&$ script=sci arttext 9. Resende MC, Azevedo EGS, Lourenço LR, Faria LS, Alves NF, Farina NP, Silva NC, Oliveira SL. Saúde mental e ansiedade em agentes comunitários que atuam em saúde da família em Uberlândia (MG, Brasil). Ciênc. saúde coletiva. [Internet]. 2011 [cited 2012 sep 13];16(4): 2115-2122. Available from: http://www.scielo.br/scielo.php?pid=S1413$81232011000400011 \&$ script=sci arttext 
10. Camelo SHH, Angerami ELS. Riscos psicossociais relacionados ao trabalho das equipes de saúde da família: percepções dos profissionais. Rev.enferm.UERJ. [Internet]. 2007 [cited 2009 nov 15] 15(4):502-50. Available from: http://www.facenf.uerj.br/v15n4/v15n4a04.pdf 11. Sousa MF, Hamann EM. Programa Saúde da Família no Brasil: uma agenda incompleta?. Ciênc. saúde coletiva. 2009, 14(Supl.1):1325-1335.

12. Arraes CO, Araújo ACO, Santos JR, Brasileiro ME. Riscos psicossociais que acometem a saúde dos trabalhadores da equipe multiprofissional da atenção básica de saúde: uma revisão de literatura. Rev Eletr Enfermagem e Nutrição. 2009. Available from:

http://www.cpgls.ucg.br/ArquivosUpload/1/File/V\%20MOSTRA \%20DE\%20PRODUO\%20CIENTIFICA/SAUDE/29-.pdf 13. Carreiro GSP, Ferreira Filha MO. Identificação de risco para adoecimento mental em profissionais de unidades de saúde da família do município de João Pessoa-PB [monography]. João Pessoa: Departamento de enfermagem em saúde pública e psiquiatria/UFPB; 2007.

14. Dejours C, Abdoucheli E, Jayet C. Psicodinâmica do trabalho: contribuições da escola Dejouriana à análise da relação prazer, sofrimento e trabalho. 1ed. 12. reimp. São Paulo: Atlas; 2011.

15. Fonseca RMGS; Egry EY. Epidemiologia Social. In: Epidemiologia social. In: Garcia TR; Egry EY. (Org.) Integralidade da atenção no SUS e sistematização da assistência de enfermagem. Porto Alegre: Artmed, 2010.

16. Guia de utilização do software Alceste: uma ferramenta de análise lexical aplicada à interpretação de discursos de atores na agricultura. 1ed. Planaltina, DF: Embrapa Cerrados, 2009. 37p.

17. Nieviroski AL, Amorim WL. Desgaste Físico, Psiquico e Social, como integrantes das "Condições de Trabalho" em organizações. Revista Interdisciplinar Aplicada. [Internet]. 2011 [cited 2012 jun 17]; 5(4):62-72. Available from:

http://rica.unibes.com.br/index.php/rica/article/viewFile/438/3 $\underline{69}$

18. Shimizu HE, Reis LS. As representações sociais dos trabalhadores sobre o Programa Saúde da Família. Ciênc. Saúde Coletiva. [Internet]. 2011 [cited 2012 sep 15];16(8):3461-3468. Available from: http://www.scielo.br/scielo.php?pid=S1413$\underline{81232011000900014 \& \text { script=sci arttext }}$

19. Marco PF, Citero VA, Moraes E, Nogueira-Martins LA. O impacto do trabalho em saúde mental: transtornos psiquiátricos menores, qualidade de vida e satisfação profissional. J Bras Psiquiatr. 2008 [cited 2009 nov 18];57(3):178-183.

20. Martins JT, Robazzi MLCC, Bobroff MCC. Рrazer e sofrimento no trabalho da equipe de enfermagem: reflexão à luz da psicodinâmica Dejouriana. Rev Esc Enferm USP. [Internet]. 2010 [cited 2009 nov 18];44(4):1107-11. Available from: http://www.scielo.br/pdf/reeusp/v44n4/36.pdf 21. Feliciano KVO, Kovacs MH, Sarinho SW. Burnout entre médicos da Saúde da Família:os desafios da transformação do trabalho. Ciênc. Saúde Coletiva. [Internet]. 2011 [cited 2012 sep 13];16(8):3373-3382. Available from:

http://www.scielo.br/scielo.php?.pid=S1413$81232011000900004 \&$ script=sci arttext

22. Lara R. Saúde do trabalhador: considerações a partir da crítica da economia política. R. Katál. [Internet]. 2011 [cited 2012 jun 16]; 14(1):78-85, jan./jun. Available from: http://www.scielo.br/pdf/rk/v14n1/v14n1a09.pdf 23. Franco TB, Merhy EE. Programa Saúde da Família: contradições de um Programa destinado à mudança do modelo tecnoassistencial para a saúde. In: Merhy EE. et al; O trabalho em saúde: olhando e experienciando o SUS no cotidiano. 4ed. São Paulo: Hucitec; 2007. p. 55-124.
24. Poldi RMV, Borges LH, Dalbello-Araujo M. Trabalho e saúde sob a ótica de domésticas e pedreiros do município da Serra, ES. Cad. psicol. soc. trab. [Internet]. 2011 [cited 2012 jun 16];14(2):161-177. Available from: http://www.revistasusp.sibi.usp.br/pdf/cpst/v14n2/v14n2a02.p df

25. Grando LH, Rolim MA. Família e transtornos alimentares: as representações dos profissionais de enfermagem de uma instituição universitária de atenção à saúde mental. Rev Latinoam Enfermagem. [Internet]. 2005 [cited 2009 nov 23];13(6):989-95. Available from: http://www.eerp.usp.br/rlae.

Artigo recebido em 05/05/2011. Aprovado para publicação em 20/06/2012. Artigo publicado em 31/03/2013. 